\title{
HEGEMONIA E MOVIMENTOS SOCIAIS: \\ A TEORIA POLÍTICA DE ERNESTO LACLAU E CHANTAL MOUFFE
}

\section{Felipe Cavaliere Tavares *}

Resumo: Este artigo tem por objetivo apresentar as principais características da teoria política desenvolvida pelo argentino Ernesto Laclau e pela belga Chantal Mouffe. Tomando por base o conceito de hegemonia formulado pelo italiano Antonio Gramsci, os autores defendem um modelo radical de democracia que se realiza através da articulação hegemônica entre os diversos movimentos sociais que combatem toda e qualquer forma de opressão, seja ela financeira, racial, de gênero ou orientação sexual.

Palavras-chave: Movimentos Sociais; Hegemonia; Democracia radical; Articulação; Direitos Humanos

\section{HEGEMONY AND SOCIAL MOVEMENTS: THE POLITICAL THEORY OF ERNESTO LACLAU AND CHANTAL MOUFFE}

Abstract: This article aims to present the main features of the political theory developed by the Argentinean Ernesto Laclau and the Belgian Chantal Mouffe. Based on the concept of hegemony formulated by the Italian Antonio Gramsci, the authors defend a radical model of democracy that is realized through the hegemonic articulation between the diverse social movements that fight any and all forms of oppression, be it financial, racial, gender or sexual orientation.

Key words: Social Movements; Hegemony; Radical democracy; Articulation; Human Rights

\section{INTRODUÇÃO}

Em 1985, o argentino Ernesto Laclau e a belga Chantal Mouffe publicam o livro Hegemonia e Estratégia Socialista: Por uma Política Democrática Radical. Sua tese central é a necessidade de criação de uma cadeia de equivalências entre as diversas lutas democráticas contra as diferentes formas de subordinação. As lutas contra o sexismo, o racismo ou a discriminação sexual, precisam ser articuladas com as tradicionais reivindicações dos trabalhadores, consolidando desta maneira um modelo radical de democracia, que não nega as conquistas liberais, mas, pelo contrário, pretende aprofundá-las. A democracia radical,

\footnotetext{
* Doutor em direito pela Universidade do Estado do Rio de Janeiro (UERJ). Professor do Centro Universitário Augusto Motta (UNISUAM). Endereço eletrônico: felipecavalieretavares@ gmail.com
}

Rev. de Movimentos Sociais e Conflitos | e-ISSN: 2525-9830 | Porto Alegre | v. 4 | n. 2 | p. 23 - 44 | Jul/Dez. 2018 
portanto, é aquela em que os tradicionais movimentos sociais de combate aos efeitos prejudiciais do capitalismo conseguem se articular com os novos movimentos de combate à opressão de gênero, racial ou de orientação sexual, através do chamado princípio de equivalência democrática.

Os autores afirmam que este modelo radical de democracia teria por base quatro elementos principais: os conceitos de poder, antagonismo, hegemonia e articulação. Em relação ao poder e ao antagonismo, eles afirmam que as relações antagônicas de poder são constitutivas da vida em sociedade e qualquer política democrática não deve ter como objetivo eliminar essas relações, o que seria impossível, mas sim transformá-las, fazer com que essas relações sejam compatíveis com os valores democráticos. ${ }^{1}$ É neste ponto que Mouffe e Laclau trazem para a sua teoria o pensamento do italiano Antônio Gramsci e suas ideias sobre hegemonia. Se o poder é estratégia e dominação, sujeito a todo tipo de manobra para sua manutenção, resta evidente que a manutenção de poder é a manutenção da hegemonia de um discurso dominante sobre outro discurso dominado. As relações sociais, na verdade, são relações em torno da disputa pela hegemonia social. Assim, dentro desta disputa, é necessário que os diversos atores políticos presentes na sociedade aberta e fragmentada identifiquem pontos nodais, ou seja, pontos em comum pelos quais valeria a pena construir uma nova identidade, que tivesse condições de se tornar hegemônica. Isso significa que os diferentes discursos políticos particulares de cada grupo são insuficientes para a conquista da hegemonia, já que são incompletos. Mas na medida em que um discurso particular qualquer agrega elementos de outros discursos, a hegemonia é possível. A este processo, dão o nome de articulação (LACLAU; MOUFFE, 2015, p.25).

Neste sentido, Mouffe e Laclau destacam o papel exercido pelos chamados novos movimentos sociais. Com este termo - novos movimentos sociais - procuram expressar uma amálgama de lutas muito diversas: urbanas, rurais, ecológicas, antiautoritárias, feministas, etc. Assim, à tradicional luta contra a opressão do capital foram somadas outras frentes de batalha. Negros, mulheres e homossexuais, por exemplo, formaram movimentos para reivindicar seus direitos e lutar pelo reconhecimento de suas próprias identidades. Contudo, tais lutas são

\footnotetext{
${ }^{1}$ Para Mouffe e Laclau, o modelo deliberativo de democracia proposto por Habermas peca exatamente por afirmar que quanto mais democrática fosse uma sociedade, menor seria a influência do poder nas relações sociais. Para eles, ao postular uma esfera pública em que o poder foi eliminado em nome de um consenso racional, Habermas nega o papel fundamental do poder na formação das identidades coletivas. Cf. MOUFFE, Chantal. Democracia, cidadania e a questão do pluralismo. In: Política e Sociedade - Revista de Sociologia Política, vol.1, n.3, Florianópolis: EDUFSC, 2003, p.13.
} 


\section{HEGEMONIA E MOVIMENTOS SOCIAIS: A TEORIA POLÍTICA DE ERNESTO LACLAU E CHANTAL MOUFFE}

independentes umas das outras, e este isolamento dificulta, segundo Mouffe e Laclau, a construção de um autêntico projeto hegemônico. Segundo eles, cabe a uma ideia radical de cidadania funcionar como um elemento articulador, estabelecendo uma verdadeira equivalência democrática entre essas diversas formas de luta. Mouffe e Laclau, porém, ressaltam que este princípio da equivalência democrática requer a formação de uma vontade coletiva entre os movimentos, pois é apenas através dela que a articulação será capaz de representar a identidade popular. Sem a formação desta vontade coletiva, a articulação entre os movimentos é uma mera aliança de interesses, incapaz de propiciar as condições políticas exigidas para a conquista da hegemonia. Para eles, portanto, a relação entre hegemonia e democracia depende, fundamentalmente, de uma estratégia política que privilegie a vontade popular, sendo, por isso mesmo, um modelo democrático populista.

Este artigo, desta forma, pretende apresentar as principais características desta teoria política desenvolvida por Mouffe e Laclau. O primeiro capítulo aborda as origens do conceito de hegemonia, desde a social democracia russa até o pensamento político de Gramsci. O segundo capítulo analisa as principais características do conceito de hegemonia formulado por Mouffe e Laclau. E o terceiro capítulo, por fim, apresenta o papel desempenhado pelos movimentos sociais neste modelo desenvolvido pelos autores, em especial naquilo que se refere à formação da identidade popular que pode permitir a conquista da hegemonia política.

\section{AS ORIGENS DO CONCEITO DE HEGEMONIA}

O conceito de hegemonia, segundo Mouffe e Laclau (2015, p. 55), deve o seu surgimento à crise que irá afetar todo o movimento teórico marxista, no início do século XX, em função das mudanças sociais causadas pelo crescimento do capitalismo industrial. O novo Estado capitalista conduziu a classe proletária a um intenso processo de fragmentação, que quebrou o sentimento de unidade de classe que o paradigma clássico considerava como essencial para o proletariado. Como lidar com essa situação de descontinuidade? Como reconstituir a unidade perdida? A incapacidade em responder a estas perguntas fez surgir uma 
incômoda lacuna no arcabouço teórico marxista, que será preenchida exatamente com o conceito de hegemonia. $^{2}$

Ainda segundo Mouffe e Laclau, o desenvolvimento histórico do conceito de hegemonia, dentro deste contexto teórico marxista, passa por três diferentes etapas: a social democracia russa; o leninismo; e a obra de Antonio Gramsci. Antes de analisar estas etapas, porém, os autores destacam a importância do pensamento de Rosa Luxemburgo. Para eles, será ela quem, no início do século XX, abordará pela primeira vez a necessidade de unificação do proletariado fragmentado, afirmando, porém, que tal fato só seria possível através da revolução. Por acreditar que o capitalismo burguês não tinha mais como se desenvolver na Alemanha, Rosa entendia que os fatos ocorridos na Rússia, no início do século passado, eram o modelo que a social democracia alemã deveria seguir. ${ }^{3}$ Ela dizia que dentro do contexto fragmentado em que se encontrava o proletariado, era inevitável que ocorressem uma série de lutas parciais, cujos resultados seriam muito mais significativos quando cada uma dessas lutas representasse, simbolicamente, um simples momento de uma luta muito mais importante - a luta contra o sistema capitalista:

Não é acima, nas pontas das direções e de sua aliança federativa, mas sim abaixo, na massa proletária organizada, onde está a garantia para a autêntica unidade do movimento operário. Na consciência de milhões de membros sindicais, partidos e sindicatos são, efetivamente, uma coisa só, a saber: a luta social democrata, em diversas formas, pela emancipação do proletariado (LUXEMBURGO, 2003, p. 102, tradução nossa). ${ }^{4}$

\footnotetext{
${ }^{2}$ Para Mouffe e Laclau, o movimento teórico marxista, antes do surgimento do conceito de hegemonia, vai tentar enfrentar o avanço do capitalismo industrial através de três diferentes ações: Primeiro, um fortalecimento do marxismo ortodoxo; depois, o revisionismo; e por fim, o sindicalismo revolucionário. Nenhuma delas, porém, será tão significativa quanto a ideia de hegemonia. Cf. LACLAU, Ernesto; MOUFFE, Chantal. Hegemonia e estratégia socialista: por uma política democrática radical. Op. Cit, p. 71-105.

${ }^{3}$ Rosa Luxemburgo não concordava com a ideia de que as condições históricas e culturais da Alemanha, diferentes daquelas existentes na Rússia, impediriam que o processo revolucionário ocorresse em terras germânicas: Não é necessário observar de muito perto para perceber que todos os objetivos econômicos da luta do proletariado russo na atual revolução são também bastante atuais para o proletariado alemão, colocando o dedo em todas as feridas da existência proletária (Tradução nossa). O texto em língua estrangeira é: "No es necesario observar muy de cerca para darse cuenta que todos los objetivos económicos de lucha del proletariado ruso en la revolución actual, tienen también una gran actualidad para el proletariado alemán, y ponen el dedo precisamente en todas las llagas de la existencia proletária". Cf. LUXEMBURGO, Rosa. Huelga de masas, partido y sindicato. Madrid: Fundación Federico Engels, 2003, p. 70.

${ }^{4} \mathrm{O}$ texto em língua estrangeira é: "No es arriba, en las puntas de las direcciones y de su alianza federativa, sino abajo, en la masa proletaria organizada, donde está la garantia para la auténtica unidad del movimiento obrero. En la conciencia del millón de miembros sindicales, partido y sindicatos son, efetivamente, una sola cosa, a saber: la lucha socialdemócrata, en diversas formas, por la emancipación del proletariado". Cf. LUXEMBURGO, Rosa. Huelga de masas, partido y sindicato. Op. cit, p. 102.
}

Rev. de Movimentos Sociais e Conflitos | e-ISSN: 2525-9830 | Porto Alegre | v. 4 | n. 2 | p. 23 - 44 | Jul/Dez. 2018 


\section{HEGEMONIA E MOVIMENTOS SOCIAIS: A TEORIA POLÍTICA DE ERNESTO LACLAU E CHANTAL MOUFFE}

Mouffe e Laclau concordam que as ideias de Rosa, naquele momento, representavam uma grande novidade dentro do cenário teórico ortodoxo da Segunda Internacional, onde a unidade de classe seria influenciada tão somente pelas leis de infraestrutura. Para eles, Rosa é a primeira a perceber a necessidade de multiplicação dos pontos de antagonismo e das formas de luta, ou seja, a primeira a perceber aquilo que ambos chamam de 'diferentes posições de sujeito'. Porém, ressaltam que para Rosa a unificação resultante das lutas parciais teria como resultado, sempre, uma unidade bem precisa, uma unidade de classe.

De qualquer forma, como visto acima, a construção do conceito de hegemonia como resposta à crise do marxismo tem o seu início na social democracia russa. Naquele momento, considerou-se que o desenvolvimento insuficiente do capitalismo burguês obrigava a classe proletária a realizar tarefas que não lhe eram próprias. No contexto russo, portanto, hegemonia é o novo tipo de relação que se estabelecia entre o proletariado e algumas tarefas alheia à sua natureza de classe, que ele deveria em algum momento assumir (LACLAU; MOUFFE, 2015, p. 111).

Durante o período leninista, a hegemonia é considerada a direção política dentro de uma aliança firmada entre grupos proletários. Através de seus partidos representativos, estes diferentes grupos estabelecem uma aliança contra um inimigo comum. ${ }^{5}$ Mas essa unidade é circunstancial, não altera a identidade de cada grupo. A aliança é feita em função de interesses convergentes, mas, em última instância, os grupos permanecem incompatíveis entre si. Estão juntos na hora de atacar o inimigo, mas depois marcharão separados (LACLAU; MOUFFE, 2015, p. 117). Assim, para o leninismo, a hegemonia nada mais era do que a direção política da aliança, exercida por determinado grupo. Esta direção política podia ser mais ou menos democrática. No primeiro caso, seria mais democrática sempre que a direção ouvisse as demandas dos grupos, articulando esses interesses variados e formando uma aliança sólida. Porém, a direção também poderia ser autoritária, o que ocorreria sempre que este grupo dirigente considerasse que era responsável por determinar os reais interesses da aliança. Neste caso, o grupo dirigente estabelece uma relação política em que é o representante dos demais

\footnotetext{
${ }^{5} \mathrm{O}$ próprio Lênin ressaltava a necessidade de participação do proletariado na revolução democrático-burguesa, uma vez que a situação específica da Rússia, naquela época, exigia o sucesso de tal revolução. Para ele, era necessário que o proletariado participasse de forma ativa em tal revolução, uma vez que esse seria o caminho mais rápido e seguro para o socialismo. Por este motivo, criticava as teses anarquistas, contrárias a esta participação. Para ele, quem desejasse caminhar para o socialismo por um caminho que não fosse a democracia política chegaria fatalmente a conclusões absurdas e reacionárias. Cf. GRUPPI, Luciano. O conceito de hegemonia em Gramsci. 2 ed. Tradução de Carlos Nelson Coutinho. Rio de Janeiro: Edições Graal, 1978, p. 7.
}

Rev. de Movimentos Sociais e Conflitos | e-ISSN: 2525-9830 | Porto Alegre | v. 4 | n. 2 | p. 23 - 44 | Jul/Dez. 2018 
grupos proletários. Mouffe e Laclau afirmam que ficou muito claro, dentro do contexto leninista, que tal grupo dirigente seria o partido político:

Uma vez que toda relação política é concebida como uma relação de representação, um substitucionismo progressivo move-se da classe ao partido (representação dos interesses objetivos do proletariado) e do partido ao Estado Soviético (representação dos interesses mundiais do movimento comunista) (LACLAU; MOUFFE, 2015, p. 122).

Inicialmente, o discurso comunista oscilaria entre o aspecto democrático e o outro, autoritário, mas à medida em que a prática democrática ganha espaço, o leninismo tem que lidar com dois problemas: Primeiro, como caracterizar a pluralidade de antagonismos que surgem entre os grupos que formam a aliança. E segundo, como manter o caráter proletário desta aliança. É aqui que torna-se fundamental o pensamento político do italiano Antonio Gramsci. $^{6}$

Mouffe e Laclau entendem que a principal contribuição de Gramsci ao pensamento político é a transição da ideia de representação dos interesses, típico do leninismo, pela ideia de articulação, o que irá fortalecer o próprio conceito de hegemonia (LACLAU; MOUFFE, 2015, p. 131). Para Gramsci, essa transição é possível quando a liderança política não se estabelece sobre uma coincidência contingencial de interesses, mas sim sobre um conjunto de ideias ou valores que são compartilhados pelos diversos setores que fazem parte do proletariado. É o que ele chama de ideologia. Esta liderança, que acima de tudo é moral e intelectual, é representada por uma espécie de vontade coletiva, formada entre forças históricas dispersas e fragmentadas, que através desta ideologia passam a formar um bloco histórico. A ideologia, assim, é o terreno constitutivo da hegemonia. Porém, Gramsci frisa que esta ideologia não é um mero sistema de ideias, mas sim um todo orgânico, fundamentado em aparatos e instituições, com alguns princípios articulatórios básicos:

Para Gramsci, é aqui que se situa o momento especificamente político, e ele se caracteriza por uma luta ideológica que tenta estabelecer a união entre objetivos econômicos, políticos e intelectuais, colocando todas as questões em torno das quais a luta se estende em um nível universal e não corporativo, criando, consequentemente, a hegemonia de um grupo social

\footnotetext{
${ }^{6}$ Para Luciano Gruppi, Antônio Gramsci é, depois de Lênin, aquele que mais atenção deu ao conceito de hegemonia. Este seria, inclusive, o grande ponto de convergência entre os dois importantes teóricos marxistas. Cf. GRUPPI, Luciano. O conceito de hegemonia em Gramsci. Op. Cit., p.1.
}

Rev. de Movimentos Sociais e Conflitos | e-ISSN: 2525-9830 | Porto Alegre | v. 4 | n. 2 | p. 23 - 44 | Jul/Dez. 2018 


\section{HEGEMONIA E MOVIMENTOS SOCIAIS: A TEORIA POLÍTICA DE ERNESTO LACLAU E CHANTAL MOUFFE}

fundamental sobre uma série de outros grupos subordinados (MOUFFE, 1979, p.180, tradução nossa). ${ }^{7}$

Gramsci percebeu que as transformações ocorridas nas sociedades capitalistas exigiam uma mudança de estratégia na forma pela qual o marxismo pretendia combater o predomínio de classe e realizar a transição da sociedade ao socialismo. ${ }^{8}$ É neste sentido que ele vai dirigir sua crítica a Trotsky, Rosa Luxemburgo e, de um modo geral, à estratégia política desenvolvida na Internacional Comunista entre os anos de 1929 e 1934, estratégia está fundamentada na equivocada suposição de que o capitalismo estava à beira de um enorme colapso. Gramsci sustentava - e a história lhe deu razão - que o capitalismo não estava prestes a desaparecer, mas sim passando por um processo de transformação (COUTINHO, 1999, p.150).

A mudança de estratégia defendida por Gramsci envolvia, inicialmente, uma compreensão ampliada do conceito de Estado. Para ele, o Estado, de uma forma geral, pode ser dividido em sociedade política e sociedade civil. A primeira, também chamada por ele de Estado-coerção, é aquela em que a classe dominante exerce o monopólio legal da repressão e da violência, através dos mecanismos de coerção típicos de uma burocracia policial ou militar. Já a sociedade civil é aquela onde ocorre a difusão das ideologias, formada por instituições como escolas, igrejas, sindicatos, partidos políticos, organizações de comunicação de massa, etc. Gramsci afirma que a razão para o fracasso da revolução socialista no ocidente é que os revolucionários tentaram aplicar ali o mesmo modus operandi empregado na Rússia czarista, sem levar em consideração as diferenças sociais existentes entre as duas realidades. Nas sociedades ocidentais, segundo ele, o avanço do capitalismo fez surgir um relativo equilíbrio entre a sociedade civil e a sociedade política, enquanto na Rússia czarista a sociedade civil era extremamente frágil, com um enorme predomínio da sociedade política, ou

\footnotetext{
${ }^{7} \mathrm{O}$ texto em língua estrangeira é: "For Gramsci this is where the specifically political moment is situated, and it is characterised by ideological struggle which attempts to forge unity between economic, political and intellectual objectives, placing all the questions around which the struggle rages on a universal, not a corporate level, thereby creating the hegemony of a fundamental social group over a series of subordinate ones".

${ }^{8}$ Giuseppe Tamburrano entende que Gramsci promoveu uma interpretação renovada do marxismo, voltada para uma filosofia em que o proletariado adquire consciência de sua posição na sociedade, de seu papel na construção da sociedade socialista. Esta visão mais crítica supera a interpretação mecanicista, que enxerga o marxismo como uma filosofia da necessidade histórica. Cf. TAMBURRANO, Giuseppe. Gramsci y la hegemonia del proletariado. In: TOGLIATTI, P. et al. (org.) Gramsci y el marxismo. Buenos Aires: Editorial Proteo, 1965, p.112.
}

Rev. de Movimentos Sociais e Conflitos | e-ISSN: 2525-9830 | Porto Alegre | v. 4 | n. 2 | p. 23 - 44 | Jul/Dez. 2018 
seja, um Estado fundamentado na coerção. Isso exigiria dos revolucionários estratégias distintas:

... nas formações orientais, a predominância do Estado-coerção impõe à luta de classes uma estratégia de ataque frontal, uma `guerra de movimento` ou ‘de manobra`, voltada diretamente para a conquista e conservação do Estado em sentido restrito; no Ocidente, ao contrário, as batalhas devem ser travadas inicialmente no âmbito da sociedade civil, visando à conquista de posições e de espaços ('guerra de posição`), da direção político-ideológica e do consenso dos setores majoritários da população, como condição para o acesso ao poder de Estado e para sua posterior conservação (COUTINHO, 1999, p.147).

Gramsci, portanto, afirma que sociedades onde há um Estado predominantemente coercitivo, os revolucionários devem implementar uma guerra de movimento, pautada em uma espécie de revolução permanente. Por outro lado, nos países ocidentais deve ser aplicada uma outra estratégia, uma guerra de posição, em que se busca, inicialmente, a conquista da hegemonia civil:

No período posterior a 1870, em virtude da expansão colonial europeia, todos estes elementos se modificam, as relações de organização internas e internacionais do Estado tornam-se mais complexas e maciças, e a fórmula jacobino-revolucionária da ‘revolução permanente` é elaborada e superada na ciência política pela fórmula de `hegemonia civil`. Verifica-se na arte política aquilo que ocorre na arte militar: a guerra de movimento transformase cada vez mais em guerra de posição, podendo-se dizer que um Estado vence uma guerra quando a prepara minuciosa e tecnicamente nos tempos de paz (GRAMSCI, 1991, p.92).

Outro aspecto abordado por Gramsci é o caráter desagregador deste capitalismo que então se desenvolvia nas sociedades ocidentais, o que fortalecia sobremaneira a ação de fragmentação da sociedade civil. Assim, a estratégia revolucionária deveria ser, inicialmente, “organizar politicamente os interesses de classe - constantemente fracionados pela própria dinâmica do capitalismo, cimentá-los entre si e projetá-los em termos de ação hegemônica" (NOGUEIRA, 2003, p.222).

Assim, a sociedade civil é o local onde ocorrem os diversos conflitos e contrastes, típicos de uma sociedade fragmentada, mas é também o palco onde se dá a luta pela hegemonia, a partir de um processo agregativo entre as partes até então fracionadas. De acordo com a teoria de Gramsci, portanto, a reconstrução de uma práxis de esquerda depende sobremaneira da articulação entre diferentes realidades sociais, onde se possa desenvolver um

Rev. de Movimentos Sociais e Conflitos | e-ISSN: 2525-9830 | Porto Alegre | v. 4 | n. 2 | p. 23 - 44 | Jul/Dez. 2018 


\title{
HEGEMONIA E MOVIMENTOS SOCIAIS: A TEORIA POLÍTICA DE ERNESTO LACLAU E CHANTAL MOUFFE
}

conceito de hegemonia complexo e multidimensional, cujo ponto de partida seja a adesão entre os oprimidos e os indignados com a injustiça (CAMPIONE, 2003, p. 62).

Gramsci estava atento para um aspecto importante deste processo de formação hegemônica, que era a questão cultural. Isto porque a construção de um novo bloco histórico não seria possível apenas pela convergência de interesses econômicos ou políticos, mas também por afinidades de natureza cultural e ideológica, como afirma Giuseppe Tamburrano:

\begin{abstract}
A ação socialista não pode ser dirigida somente à conquista do poder político, porque cedo ou tarde entraria em confronto não apenas com os interesses dos capitalistas e de seus apêndices parasitários, mas também com os interesses da massa atraída pelo socialismo, mas que ainda não foi conquistada ideologicamente para a ação socialista. A ação socialista deve ter como objetivo aderir às condições materiais e intelectuais próprias de cada país, para unificar politica e ideologicamente todas as massas interessadas pelo socialismo, ou seja, promover a direção cultural e moral, a hegemonia socialista, ao criar um novo bloco histórico socialista (TAMBURRANO, 1965, p.116, tradução nossa). ${ }^{9}$
\end{abstract}

É aqui Gramsci vai destacar o papel dos partidos e dos intelectuais, formulação conceitual radicalmente nova dentro do marxismo. ${ }^{10}$ Se a questão ideológica é essencial na luta pela hegemonia, então o trabalho dos partidos e dos intelectuais na construção ou desconstrução de uma ideia é também essencial para a formação ou conservação de um bloco histórico (COUTINHO, 1999, p.74). Neste caso, caberia a eles articular a união das forças populares então fragmentadas, na busca da superação das possíveis divergências entre essas forças. Assim, é bem evidente a intenção de Gramsci em ampliar o debate teórico marxista, indo além da disputa de classes, mas sem deixar de reconhecer sua importância primordial. ${ }^{11}$ O conceito de `guerra de posição` está inserido neste contexto, sendo uma resposta ao viés unitário do marxismo leninista, valorizando os novos conflitos que surgiam na sociedade:

\footnotetext{
${ }^{9}$ O texto em língua estrangeira é: "La acción socialista no puede ser dirigida sólo a la conquista del poder político, porque antes o después tropezaria no sólo con los intereses de los capitalistas y de sus apéndices parasitários, sino también con los intereses de la masa atraída por el socialismo pero que aún no ha sido conquistada ideologicamente para la acción socialista. La acción socialista debe apuntar adhiriendo a las condiciones materiales e intelectuales propias de cada pais, a unificar politica e ideologicamente todas las masas interesadas por el socialismo, es decir, instaurar la dirección cultural y moral, la hegemonia socialista, al crear el nuevo bloque histórico socialista".

${ }^{10}$ Referindo-se ao pensamento político de Maquiavel, Gramsci diz que o partido exerce na modernidade o mesmo papel que o Príncipe antes exercia. Cf. TAMBURRANO, Giuseppe. Gramsci y la hegemonia del proletariado. Op. Cit. p. 114.

${ }^{11}$ Carlos Nelson Coutinho afirma que, para além da óbvia vinculação com o marxismo, é importante frisar que na construção de sua teoria da hegemonia, Gramsci dialogou também com outras grandes figuras da filosofia política moderna, como Maquiavel, Rousseau e Hegel. Cf. COUTINHO, Carlos Nelson. Gramsci: um estudo sobre seu pensamento político. Op. Cit,p. 272.
}

Rev. de Movimentos Sociais e Conflitos | e-ISSN: 2525-9830 | Porto Alegre | v. 4 | n. 2 | p. 23 - 44 | Jul/Dez. 2018 
Resgata-se assim o conceito de revolução, mas sob a forma de um processo de laboriosa gestação e não de um acontecimento único e irreversível, e com um conteúdo de transformação radical, não limitado ao poder político e às relações de produção fundamentais, mas aberto à ruptura de todas e de cada uma das relações marcadas pela opressão e pela desigualdade (CAMPIONE, 2003, p.54).

\section{O CONCEITO DE HEGEMONIA PARA MOUFFE E LACLAU}

Apesar de destacarem a importância do pensamento político de Gramsci, retomando, inclusive, o seu conceito de hegemonia, o fato é que Mouffe e Laclau pretendem ir além daquilo que foi desenvolvido por ele. Consideram que a teoria de Gramsci é incoerente e não supera plenamente o dualismo do marxismo clássico, uma vez que crê na existência de um princípio unificante, vinculado a um fundamento ontológico. Esta contradição ocorre porque, por um lado, Gramsci, corretamente, considera que a classe proletária precisa articular suas lutas democráticas, mas não consegue escapar de forma integral do essencialismo, uma vez que afirma que o papel articulador é determinado pela infraestrutura.

Porém, mesmo para Gramsci, o cerne último da identidade do sujeito hegemônico é constituído num ponto externo ao espaço que ele articula: a lógica de hegemonia não desenvolve todos os seus efeitos desconstrutivos no terreno teórico do marxismo clássico. Testemunhamos, contudo, a queda deste último reduto do reducionismo de classe, na medida em que a unidade e homogeneidade dos sujeitos de classe têm se dividido num conjunto de posições precariamente integradas, as quais, uma vez abandonada a tese do caráter neutro das forças produtivas, não podem ser referidas a qualquer ponto necessário de unificação futura. A lógica de hegemonia, como uma lógica de articulação e contingência, passou a determinar a própria identidade dos sujeitos hegemônicos (LACLAU; MOUFFE, 2015, p.154).

É necessário, portanto, superar os ensinamentos de Gramsci, o que significa, na prática, desvincular o conceito de hegemonia de qualquer traço de essencialismo. Para consolidar este rompimento, Mouffe e Laclau utilizam-se do arcabouço teórico desenvolvido 


\section{HEGEMONIA E MOVIMENTOS SOCIAIS: A TEORIA POLÍTICA DE ERNESTO LACLAU E CHANTAL MOUFFE}

por alguns autores ligados ao pós-estruturalismo, como por exemplo os franceses Jacques Derrida e Jacques Lacan. ${ }^{12}$

Em relação a Derrida e seu desconstrutivismo, é Laclau quem melhor demonstra sua importância para a política. Ele afirma que Derrida, ao elaborar seu conceito de "democracia por vir", demonstra a necessidade contínua de se manter aberta a relação com o outro, sendo que esta abertura nunca é definida a priori. Para o argentino, portanto, o desconstrutivismo ressalta uma importante dimensão da política: seu caráter de incompletitude. Ele diz que politizar uma sociedade é uma operação que provoca uma situação de constante tensão:

A "politização" da sociedade opera um deslocamento duplo: por um lado, há, certamente, uma expansão da política em detrimento do social; mas, por outro lado, a politização também envolve a produção contingencial de elos sociais e, neste sentido, uma descentralização da sociedade. Para colocar a questão em outros termos: aquilo que torna a política possível - a contingência dos atos de instituição - é também o que a torna impossível, uma vez que, em última análise, nenhum ato institucional é plenamente realizável. [...] Assim, a condição de possibilidade de algo é também, ao mesmo tempo, sua condição de impossibilidade. Como se vê, já se está no terreno da desconstrução. Esta torna possível uma virada crucial na teoria política por: (a) o alargamento do campo da indecidibilidade estrutural; e (b) a preparação do terreno para uma teoria da decisão, tomada no campo da indecidibilidade (LACLAU, 1996, p.50. tradução nossa).

O desconstrutivismo, portanto, amplia a atuação e a importância da própria esfera política, pois demonstra este caráter `indecidível de suas decisões. Assim, o que Laclau deixa claro é que o descontrutivismo deve ser sempre complementado por uma teoria da hegemonia. Pois se o ato de desconstruir consiste em demonstrar o caráter indecidível da objetividade social, a hegemonia fornece exatamente o elemento teórico que permite a tomada de decisões, sempre contingenciais, dentro desta realidade (CRITCHLEY; MARCHART, 2004, p.5).

Em relação a Lacan, Mouffe e Laclau entendem que sua teoria psicanalítica permite uma abordagem tanto no campo da ética como no campo da política, convergindo para

\footnotetext{
${ }^{12}$ Mouffe é taxativa em afirmar a importância do pós-estruturalismo para a teoria da hegemonia: Toda a questão da hegemonia relaciona-se com a perspectiva pós-estruturalista e a ideia de que a hegemonia é transformada pela articulação. Não é possivel se compreender a ideia de hegemonia - da forma como a colocamos em Hegemonia e estratégia socialista - de forma independente às quarto teses sobre a construção discursiva da realidade e do social. O texto em língua estrangeira é: "The whole question of hegemony is linked to the poststructuralist perspective, and the idea that hegemony is transformed by articulation. You cannot understand the idea of hegemony - as we have put it forward in HSS - independently of four thesis about the discursive construction of reality and the social". Cf. CARPENTIER, Nico; CAMMAERTS, Bart. (2006) Hegemony, democracy, agonism and journalism: an interviewwith Chantal Mouffe. Journalism studies, 7 (6). pp. 964-975.
}

Rev. de Movimentos Sociais e Conflitos | e-ISSN: 2525-9830 | Porto Alegre | v. 4 | n. 2 | p. 23 - 44 | Jul/Dez. 2018 
questões que ambos trabalham dentro do chamado pluralismo agonístico. Para Lacan, o funcionamento psíquico do ser humano estrutura-se em três dimensões - o Real, o Simbólico e o Imaginário - que se articulam em uma espécie de nó borromeano, ou seja, formam círculos autônomos, intercambiáveis, de tal forma entrelaçados que se um deles deixa de exercer força sobre os outros dois, o nó se desmancha e todos ficam livres, sem formar um par.

O Imaginário é o campo daquilo que se vê ou daquilo que se pensa que se vê dos objetos. É aqui que surgem as fantasias, as crenças, as ilusões, os conceitos e preconceitos. Compreende toda a abordagem freudiana sobre o narcisismo (JORGE; FERREIRA, 2005, p.32). É no Imaginário, portanto, que nascem as demandas e, consequentemente, as frustrações, a insatisfação, a tal sensação de imcompletitude. Quando as suas demandas são atendidas, o indivíduo alcança a felicidade, mas a frustração da demanda leva à dor a à tristeza. Essa mistura de situações felizes e dolorosas constitui a forma pela qual os indivíduos interpretam e interagem com o mundo. É neste contexto que surge o segundo elo, o Simbólico, que é o campo das relações entre inconsciente e linguagem. ${ }^{13}$ É aqui que as palavras, sons e conceitos vão se transformando em símbolos, à medida em que são interpretados pelos indivíduos. O Real - que não deve ser interpretado como a realidade - é o campo da "coisa" (das ding), daquilo que não pode ser nomeável, é o que sobra do Imaginário e que o Simbólico não consegue capturar. Portanto, o Real é aquilo que não pode ser representado nem por palavras nem por imagens. Neste sentido, é possível se afirmar que "a única via de o real se inscrever na estrutura é através dos efeitos de sua própria impossibilidade. O real é o que ex-siste assim como o simbólico é o que insiste e o imaginário é o que faz consistência” (JORGE; FERREIRA, 2005, p.32). É o impossível, aquilo que escapa à subjetividade humana, escapa ao desejo do homem de ter domínio completo sobre si mesmo:

Essa Coisa, da qual todas as formas criadas pelo homem são do registro da sublimação, será sempre representada por um vazio, precisamente pelo fato de ela não poder ser representada por outra coisa - ou, mais exatamente, de ela não poder ser representada senão por outra coisa (LACAN, 2008, p.158).

\footnotetext{
${ }^{13}$ Embora não se possa classifica-lo como estruturalista, é inegável a importância do estruturalismo na obra de Lacan, em especial os estudos de linguística desenvolvidos por Ferdinand de Saussure. É a partir dele que Lacan desenvolve sua lógica do significante para construir uma relação entre o inconsciente e a linguagem. Cf. JORGE, Marco Antonio Coutinho; FERREIRA, Nadiá Paulo. Lacan, o grande freudiano. Op. Cit., p. 44-50.
} 


\section{HEGEMONIA E MOVIMENTOS SOCIAIS: A TEORIA POLÍTICA DE ERNESTO LACLAU E CHANTAL MOUFFE}

Tal fato terá consequências diretas na relação que se estabelece entre o indivíduo e a sociedade, na medida em que os efeitos do Real são convertidos para uma abordagem político-social, na medida em que este Real é exatamente aquilo que não pode ser simbolizado, a impossibilidade da produção de sentidos (MENDONÇA, 2014, p.135). Assim, a ética do Real desenvolvida por Lacan, no entendimento de Mouffe, é perfeitamente compatível com uma democracia plural, na medida em que é uma ética que se esforça para criar entre os indivíduos uma nova forma de vínculo, um vínculo que reconhece os indivíduos como indivíduos divididos. Além disso, é uma ética que não sonha com uma reconciliação impossível, visto que compreende o caráter irredutível e inerradicável da violência e do antagonismo (MOUFFE, 2000, p. 139).

Para Mouffe e Laclau, portanto, o desejo do marxismo clássico em encontrar - e representar - os verdadeiros interesses da classe proletária, não pode ser realizado, uma vez que a fragmentação que atingiu a vida em sociedade impede que a classe proletária exista como tal, ou seja, de forma homogênea e unificada. A ideia de classe é substituída por um conjunto de diferentes grupos, ou diferentes posições de sujeito, precariamente integrados, que não possuem nenhum ponto necessário de unificação futura ${ }^{14}$. Não há, portanto, um princípio teórico qualquer que possa conduzir essas posições fragmentadas a uma unificação posterior, pelo menos não no sentido de necessidade histórica imaginado pelo marxismo clássico. A própria identidade dos sujeitos hegemônicos depende de um processo de construção discursiva. Assim, fundamentados nesta base pós-estruturalista, Mouffe e Laclau afirmam que a construção de um conceito de hegemonia que supere àquele desenvolvido por Gramsci requer um complexo movimento estratégico, uma negociação entre superfícies discursivas mutuamente contraditórias. Em suma, para os autores, a hegemonia é, tão somente, um tipo de relação política, constituída através de uma articulação contingencial. Não há uma classe ou poder dominante dentro de uma formação hegemônica.

\section{HEGEMONIA, MOVIMENTOS SOCIAIS E POPULISMO}

\footnotetext{
${ }^{14}$ Além dos marxistas tradicionais, Mouffe critica também autores como Alain Touraine e Andre Gorz, para quem a classe dos trabalhadores foi substituída pelos novos movimentos sociais (Touraine) ou pela não-classe dos não-trabalhadores. Para ela, esta substituição também seria típica de um essencialismo que deve ser combatido. Cf. CARPENTIER, Nico; CAMMAERTS, Bart. (2006) Hegemony, democracy, agonism and journalism: an interviewwith Chantal Mouffe. Journalism studies, 7 (6). pp. 964-975.
}

Rev. de Movimentos Sociais e Conflitos | e-ISSN: 2525-9830 | Porto Alegre | v. 4 | n. 2 | p. 23 - 44 | Jul/Dez. 2018 
Mouffe e Laclau admitem que a pluralidade típica da sociedade contemporânea (múltiplas posições de sujeito, que conduzem a variadas formas de antagonismo, que por sua vez permitem a formação de múltiplas cadeias de equivalência, criando variados espaços políticos) é mais visível na crescente autonomização das formas de luta. A expansão dos novos movimentos sociais é o resultado desta autonomização. ${ }^{15}$ Ressaltam, porém, que tal autonomização não representa uma incompatibilidade com a hegemonia. Tal fato só ocorreria se os movimentos sociais fossem desconectados uns dos outros. Mas na medida em que as identidades destes movimentos dependem de certas condições políticas e sociais, a autonomia deve ser compreendida dentro de uma luta hegemônica mais vasta. A identidade dos movimentos, assim, não é indiferente ao que acontece a sua volta e, por este motivo, é sempre incompleta:

Novos movimentos sociais muitas vezes almejam ao reconhecimento de
identidades, mas a própria ideia de 'identidade' não é ela mesma plenamente
constituída. Na verdade, uma vez que a 'identificação' não pode ser reduzida
à 'identidade', é importante se considerar a incomensurabilidade ou espaço
entre elas. Isso não significa que a impossibilidade da 'identidade' adquirir
uma completa definição prejudica a causa dos movimentos sociais. Pelo
contrário, essa incompletude é essencial para o projeto da própria
hegemonia. Nenhum movimento social pode, na verdade, se considerar uma
articulação política democrática e progressista sem presumir e
operacionalizar a negatividade existente no cerne de sua identidade
(BUTLER; LACLAU; ZIZEK, 2000, p.1-2, tradução nossa). ${ }^{16}$

Assim, haverá situações em que tais movimentos buscarão fortalecer sua autonomia, ou seja, a sua própria luta e outros em que a busca será por uma aliança com outros movimentos:

\footnotetext{
${ }^{15}$ Mouffe e Laclau consideram essa nomenclatura pouco satisfatória, mas admitem que ela representa os grupos que reivindicam estes novos direitos. Porém, ressaltam que boa parte destes novos movimentos sociais valorizam a autonomia individual, que conduz à necessidade de reconhecimento das diversas identidades culturais. Este individualismo substitui a tradicional ideia de lutas coletivas, o que certamente é uma das razões para a insatisfação da esquerda tradicional com estas novas reivindicações, acusando-as de serem `liberais`. Cf. LACLAU, Ernesto; MOUFFE, Chantal. Hegemonia e estratégia socialista: por uma política democrática radical. Op. Cit, p. 249.

${ }^{16} \mathrm{O}$ texto em língua estrangeira é: "New social movements often rely on identity-claims, but 'identity” itself is never fully constituted; in fact, since identification is not reducible to identity, it is importante to consider the incommensurability or gap between them. It does not follow that the failure of identity to achieve complete determination undermines the social movements at issue; on the contrary, that incompleteness is essential to the project of hegemony itself. No social movement can, in fact, enjoy its status as an open-ended, democratic political articulation without presuming and operationalizing the negativity at the heart of identity".
}

Rev. de Movimentos Sociais e Conflitos | e-ISSN: 2525-9830 | Porto Alegre | v. 4 | n. 2 | p. 23 - 44 | Jul/Dez. 2018 


\section{HEGEMONIA E MOVIMENTOS SOCIAIS: A TEORIA POLÍTICA DE ERNESTO LACLAU E CHANTAL MOUFFE}

... as formas desta luta empreendida por movimentos antirracistas passarão em parte pela autonomização de certas atividades e formas organizacionais; em parte, por sistemas de alianças com outras forças; e em parte, pela construção de sistemas de equivalência entre conteúdos de diferentes movimentos. Pois, nada pode consolidar mais as lutas antirracistas do que a construção de formas estáveis de sobredeterminação entre conteúdos tais como antirracismo, antissexismo e anticapitalismo, os quais, por si sós, não necessariamente tenderiam a convergir (LACLAU, MOUFFE, 2015, p.222).

É neste ponto que a teoria de Mouffe e Laclau relaciona os conceitos de hegemonia e democracia. Segundo eles, para que um projeto político possa servir como um modelo alternativo ao modelo hegemônico neoliberal, deve assumir sua condição radicalmente democrática e fortalecer a articulação hegemônica entre novas e antigas formas de resistência, (como por exemplo o antirracismo, o anti-sexismo, e o anticapitalismo), expandindo as cadeias de equivalência e permitindo a elas encontrar um espaço de filiação a partir de uma matriz radicalmente democrática:

O fortalecimento das lutas democráticas específicas requer, portanto, a expansão de cadeias de equivalência que se estendam a outras lutas. A articulação equivalencial entre antirracismo, antissexismo e anticapitalismo, por exemplo, requer uma construção hegemônica que, em certas circunstâncias, pode ser a condição para a consolidação de cada uma destas lutas. A lógica da equivalência, então, levada às suas últimas consequências, implicaria na dissolução da autonomia dos espaços em que cada uma destas lutas é constituída, não necesariamente porque algumas delas se subordinassem a outras, mas porque todas elas se tornaram, rigorosamente falando, símbolos equivalentes de uma luta única e indivisível (LACLAU, MOUFFE, 2015, p.271).

Nesta democracia radical, a articulação hegemônica representa a própria ideia de cidadania, que Mouffe chama, portanto, de cidadania radical. Tal conceito de cidadania difere bastante daquele existente no modelo democrático liberal. Isto ocorre porque, segundo Mouffe, "o que nós compartilhamos e que nos faz cidadãos em um regime democrático liberal não é uma noção substantiva do bem, mas um conjunto de princípios políticos específicos desta tradição: os princípios de liberdade e igualdade para todos” (MOUFFE, 1992, p.231). Ser um cidadão é reconhecer a autoridade de tais princípios e as regras que os incorporam, têlos como informadores da nossa opinião política e das nossas ações. Estar associado em termos de reconhecimento dos princípios democrático-liberais: este é o significado da cidadania que Mouffe quer propor. Isso implica encarar a cidadania não como um estatuto

Rev. de Movimentos Sociais e Conflitos | e-ISSN: 2525-9830 | Porto Alegre | v. 4 | n. 2 | p. 23 - 44 | Jul/Dez. 2018 
legal, mas como uma forma de identificação, um tipo de identidade política, criada através desta interpretação radical dos princípios da igualdade e liberdade. Algo que deverá ser construído, e não empiricamente determinado.

É uma identidade política comum de pessoas, que podem estar empenhadas em muitos empreendimentos com finalidades diferentes e com diversas concepções de bem, mas que, na procura da sua satisfação e na execução de suas ações, aceitam submeter-se às regras prescritas pela respublica. $\mathrm{O}$ que as liga é o reconhecimento de um conjunto de valores ético-políticos. Neste caso, a cidadania não é apenas uma identidade entre outras, tal como no liberalismo, ou a identidade dominante que se sobrepõe a todas as outras, como no republicanismo cívico. É um princípio articulador, que afecta as diferentes posições de sujeito do agente social [...] ao mesmo tempo que permite uma pluralidade de compromissos e o respeito pela liberdade individual (MOUFE, 1996, p.96).

A cidadania radical, portanto, é a identificação coletiva entre as exigências democráticas de uma diversidade de novas posições de sujeito, como é o caso das reivindicações feitas por movimentos de mulheres, negros, homossexuais, trabalhadores, agricultores, entre outros. O que se pretende, claramente, é ampliar os elementos da tradição democrática liberal, concebendo os direitos não de uma forma individualista, mas sim como verdadeiros "direitos democráticos", direitos que, embora na titularidade do indivíduo, só podem ser exercidos coletivamente, quando fundamentados na existência de direitos iguais para todos. O objetivo é construir uma cadeia de equivalências entre todas essas diferentes demandas, de forma a articulá-las pelo princípio da equivalência democrática e tornar possível uma hegemonia política. Mouffe afirma, ainda, que a formação desta cadeia de equivalências só é possível quando se define um adversário em comum, pois é isso que vai garantir a unidade da cadeia. ${ }^{17}$ Assim, fica bem evidente que este modelo radical de democracia não pode ser fundamentado em uma mera aliança de interesses, uma vez que neste cenário os envolvidos mantêm sua constituição inicial. A democracia radical relaciona-se com o princípio da equivalência democrática, que modifica a identidade das forças que integram a aliança. Para que a defesa dos interesses do trabalhador não se realize às custas dos direitos das mulheres ou dos imigrantes, é preciso que se estabeleça uma equivalência entre essas

\footnotetext{
${ }^{17}$ É por este motivo que Mouffe ainda acredita na importância da divisão política tradicional entre `direita`e ‘esquerda`, desde que tal divisão não seja feita de uma forma essencialista, onde tais conceitos estão congelados e imunes a alterações. Cf. CARPENTIER, Nico; CAMMAERTS, Bart. (2006) Hegemony, democracy, agonism and journalism: an interviewwith Chantal Mouffe. Journalism studies, 7 (6). pp. 964-975.
}

Rev. de Movimentos Sociais e Conflitos | e-ISSN: 2525-9830 | Porto Alegre | v. 4 | n. 2 | p. 23 - 44 | Jul/Dez. 2018 


\section{HEGEMONIA E MOVIMENTOS SOCIAIS: A TEORIA POLÍTICA DE ERNESTO LACLAU E CHANTAL MOUFFE}

lutas, é necessário que os movimentos sociais consigam estabelecer uma verdadeira vontade coletiva, capaz de representar uma identidade popular.

Esta necessidade de que a articulação entre os movimentos sociais seja capaz de representar a identidade popular foi aprofundada por Laclau em seu último livro, 'On Populist Reason`, onde ele relaciona os conceitos de hegemonia e populismo, procurando combater os preconceitos e equívocos que geralmente se associam ao conceito do que seja o populismo. Para ele, o populismo é ele próprio resultado de um processo de construção política, afastando qualquer ideia de que seja uma ideologia, uma anomalia ou um subdesenvolvimento irracional da democracia representativa (LOPES; MENDONÇA, 2013, p.11). Para ele, esta visão que denigre o populismo é mais um exemplo de subestimação da vida política:

O que essa rejeição tão desdenhosa implica é, segundo penso, a subestimação da política tout court e a afirmação de que a gestão da comunidade cabe a um poder administrativo cuja fonte de legitimidade é o conhecimento apropriado daquilo que constitui uma "boa" comunidade. Esse tem sido, ao longo dos séculos, o discurso da filosofia política, e Platão foi o primeiro a instituí-lo. O populismo sempre foi relacionado a um excesso perigoso, que questiona os moldes bem delineados de uma comunidade racional. Minha tarefa, portanto, tal como a concebi, foi esclarecer as lógicas específicas inerentes a esse excesso e argumentar que, longe de corresponderem a um fenômeno marginal, elas estão inscritas no funcionamento real de quaisquer espaços comunitários (LACLAU, 2013, p.27).

Pode-se dizer que Laclau, ao trazer à tona o tema do populismo, deseja na verdade determinar como se constrói o conceito de povo, como este se torna um importante ator histórico, o que para ele é algo que relaciona-se diretamente com a ideia de articulação hegemônica. Não basta que haja a relação de equivalência, é necessário que ela seja capaz de construir uma identidade popular, algo que é quantitativamente maior do que a simples soma dos laços de equivalência. Sem essa identidade popular, as relações de equivalência, segundo Laclau, não conseguem ir muito além de um vago sentimento de solidariedade. Assim, as equivalências se cristalizam através de uma espécie de identidade discursiva que, através de uma inversão do relacionamento, deixam de se subordinar às demandas iniciais e passam a se comportar como seu próprio fundamento. Para Laclau, é isto o que constitui o 'povo' do populismo, aquilo que ele descreveu como operação hegemônica. Portanto, "não existe 
hegemonia sem a construção de uma identidade popular a partir de uma pluralidade de demandas democráticas" (LACLAU, 2013, p.152).

Criticado por defender ideias ultrapassadas e totalitárias, ${ }^{18}$ Laclau afirma que a relação entre populismo e democracia é absolutamente possível, ou seja, a construção do conceito de povo é, sob outro prisma, a construção de uma vontade coletiva e como tal até pode representar uma ideia totalitária, mas também pode seguir um caminho profundamente democrático. Tudo depende de como a articulação será feita e, como visto, "o espectro de possíveis articulações é muito mais diversificado do que a simples oposição totalitarismo/democracia parece sugerir" (LACLAU, 2013, p.242). Para Laclau, portanto, a possibilidade da democracia depende da construção de um 'povo' democrático. E neste cenário, o modelo de democracia que se relaciona melhor com tal realidade é a democracia radical, apresentada por ele e Mouffe em Hegemonia e Estratégia Socialista. ${ }^{19}$

Mouffe, em seus trabalhos mais recentes, reforçou ainda mais a importância do conceito de populismo, afirmando que a radicalização da democracia só é possível através de um 'populismo de esquerda', que é aquele compromissado não apenas com os diferentes tipos de demandas democráticas, mas também com a questão político-partidária. Além desta liderança política, Mouffe entende que a formação da vontade coletiva depende fundamentalmente da ação no campo da cultura. Demonstrando mais uma vez a base gramsciana da sua teoria, Mouffe afirma que a ação intelectual e moral é vital para a conquista da hegemonia, dada a importância do campo cultural na divulgação e manutenção de ideais que se pretendem hegemônicos. É através da prática artística e intelectual que determinados conceitos podem ser subvertidos, substituídos por outros que funcionem como estímulo à

\footnotetext{
${ }^{18}$ Um desses críticos é o esloveno Slavoj Zizek que em 2006 publica o artigo `Against the Populist Temptation`, onde faz críticas (e alguns elogios, é verdade) ao conceito de populismo elaborado por Laclau. Zizek afirma que Laclau prefere trabalhar com o conceito de populismo em detrimento do conceito de luta de classes em função do fato de que esta luta acredita na existência de um agente político privilegiado, a classe dos trabalhadores, enquanto o populismo permite uma matriz neutra, uma disputa em aberto, cujo conteúdo é definido a partir da luta por hegemonia, sempre contingencial. Cf. ZIZEK, Slavoj. Against the populism temptation. In: Critical Inquiry, Chicago, 2006, n. 32:3, p.551-574. Disponível em http://jdeanicite.typepad.com/i_cite/files/zizek_against_the_populist_temptation.pdf. Acesso em 10 jun. 2017.

${ }^{19}$ Mouffe e Laclau ressaltam que esta identidade popular, contudo, não pode ser tratada como definitiva, total, sob pena de cair no essencialismo da teoria de Gramsci. A equivalência democrática é tão precária quanto todas as outras identidades sociais e, por isso mesmo, deve assumir seu caráter incompleto e contingencial. Cf. . LACLAU, Ernesto; MOUFFE, Chantal. Hegemonia e estratégia socialista: por uma política democrática radical. Op. Cit, p. 283.
} 


\section{HEGEMONIA E MOVIMENTOS SOCIAIS: A TEORIA POLÍTICA DE ERNESTO LACLAU E CHANTAL MOUFFE}

conquista da hegemonia. A luta pela hegemonia, portanto, não representa necessariamente uma completa rejeição à ordem estabelecida, mas sim um processo de desarticulação e rearticulação, coerente com aquilo que Gramsci chamou de guerra de posição. Para ela, se esta guerra por posição envolve o campo cultural, a força que a mídia exerce na formação do senso comum não pode ser ignorada. Por isso, os partidos e movimentos sociais devem lutar para reverter o posicionamento hegemonicamente capitalista da mídia tradicional, em vez de considerar que nada pode ser feito em relação a isto. (GALVÁN; MOUFFE, 2016, p.109)

\section{CONCLUSÃO}

A conquista da hegemonia, para Mouffe e Laclau, é um processo de construção política. Por isso, a teoria desenvolvida por eles é, acima de tudo, um projeto político para a realização dos valores democráticos, fundamentado no conceito gramsciano de hegemonia, mas interpretado e desenvolvido a partir dos ideais apresentados pelo pós-estruturalismo. Para eles, a hegemonia depende de uma articulação entre os diferentes movimentos sociais, que se caracterizam pela luta contra qualquer tipo de opressão. Esta articulação, porém, precisa ser mais profunda do que uma mera aliança de interesses, sendo necessário que os movimentos construam uma vontade coletiva, que garanta a identidade popular da articulação.

Pode-se concluir com a afirmação de que a teoria da hegemonia de Mouffe e Laclau é extremamente significativo para a atual realidade brasileira, em que os ideais neoliberais e conservadores de direita estão cada vez mais articulados e hegemônicos. Cabe aos movimentos sociais e também aos partidos políticos de esquerda prepararem-se de forma adequada para o difícil combate que terão que travar na luta contra o capitalismo, o patriarcado, o racismo e a homofobia. Há alguns anos, Laclau escreveu que a América Latina era um grande exemplo de sucesso para a Europa, com seus governos populares de esquerda (Brasil, Argentina, Uruguai, Bolívia, Venezuela e Equador) implementando medidas democráticas de imenso valor para o combate à opressão, além de uma evidente mobilização social. Porém, a esperança de que este modelo conseguisse se propagar geograficamente tornou-se uma grande frustração, na medida em que as políticas de esquerda de então, bem como seus governantes, não conseguiram, em sua grande maioria, sustentar-se ao longo do tempo, e a esquerda da América Latina vive hoje um período de grave crise política e econômica. Porém, a luta por uma sociedade economicamente mais justa e fraterna, onde

Rev. de Movimentos Sociais e Conflitos | e-ISSN: 2525-9830 | Porto Alegre | v. 4 | n. 2 | p. 23 - 44 | Jul/Dez. 2018 
todos os cidadãos possuem direitos sociais básicos e são tratados com igualdade e liberdade, independente da sua cor, origem, gênero ou orientação sexual, é uma luta que não permite qualquer tipo de desânimo. É preciso continuar sempre em frente, corrigindo os erros cometidos e formulando novas teorias para a superação das atuais relações de poder, que garantem a hegemonia política e econômica para estes grupos que perpetuam a opressão das minorias. A democracia radical de Mouffe e Laclau é uma dessas teorias.

\section{REFERÊNCIAS BIBLIOGRÁFICAS}

CAMPIONE, Daniel. Hegemonia e contra-hegemonia na América Latina. In: COUTINHO, Carlos Nelson; TEIXEIRA, Andréa de Paula. (org) Ler Gramsci, entender a realidade. Rio de Janeiro: Civilização Brasileira, 2003.

CARPENTIER, Nico; CAMMAERTS, Bart. (2006) Hegemony, democracy, agonism and journalism: an interviewwith Chantal Mouffe. Journalism studies, 7 (6). pp. 964-975.

COUTINHO, Carlos Nelson. Gramsci: um estudo sobre seu pensamento político. Rio de Janeiro: Civilização Brasileira, 1999.

CRITCHLEY, Simon; MARCHART, Oliver. Introduction. In: CRITCHLEY, Simon; MARCHART, Oliver. Laclau: a critical reader. New York: Routledge, 2004.

DERRIDA, Jacques. Remarks on deconstruction and Pragmatism. In: MOUFFE, Chantal (Org) Deconstruction and pragmatism. London: Routledge, 1996.

GALVÁN, Íñigo Errejón; MOUFFE, Chantal. Podemos: in the name of the people. London: Lawrence and Wishart Limited, 2016.

GASCHÉ, Rodolphe. How empty can empty be? On the place of the universal. In: CRITCHLEY, Simon; MARCHART, Oliver. Laclau: a critical reader. London: Routledge, 2004.

GRAMSCI, Antonio. Maquiavel, a política e o Estado moderno. 8 ed. Rio de Janeiro: Civilização Brasileira, 1991.

GRUPPI, Luciano. O conceito de hegemonia em Gramsci. 2 ed. Tradução de Carlos Nelson Coutinho. Rio de Janeiro: Edições Graal, 1978. 
JORGE, Marco Antonio Coutinho; FERREIRA, Nadiá Paulo. Lacan, o grande freudiano. Rio de Janeiro: Zahar, 2005.

LACAN, Jacques. O seminário, livro 7: a ética da psicanálise. Rio de Janeiro: Jorge Zahar Ed., 2008.

LACLAU, Ernesto. A razão populista. São Paulo: Três Estrelas, 2013.

Deconstruction, pragmatismo, hegemony. In: MOUFFE, Chantal (Org.).

Deconstruction and pragmatism. London: Routledge, 1996.

Emancipação e diferença. Rio de Janeiro: EdUERJ, 2011.

LACLAU, Ernesto. New Reflections on the Revolution of our Time. London: Verso, 1990.

Os novos movimentos sociais e a pluralidade do social. In: Revista Brasileira de Ciências Sociais, vol.2, p.41-47.

Structure, history and the political. In: BUTLER, Judith; LACLAU, Ernesto; ZIZEK, Slavoj. Contingency, Hegemony, Universality: Contemporary dialogues on the left. London: Verso, 2000.

Why Constructing a People is the Main Task of the Radical Politics. In: Critical Inquiry, Chicago, 2006, n. 32:4, p. 646-680, p.646. Disponível em http://www.journals.uchicago.edu/action/showCitFormats?doi=10.1086/508086. Acesso em 02 de março de 2016.

; MOUFFE, Chantal. Hegemonia e estrategia socialista: por uma política democrática radical. São Paulo: Intermeios; Brasília: CNPq, 2015.

Pós-marxismo sem pedido de desculpas. In: LOPES, Alice Casimiro; MENDONÇA, Daniel de. A teoria do discurso de Ernesto Laclau. São Paulo: Annablume, 2015.

; ZAC, Lilian. Minding the gap: the subject of politics. In: LACLAU, Ernesto (org.). The making of political identities. London: Verso, 1994.

LOPES, Alice Casimiro; MENDONÇA, Daniel de. O populismo na visão inovadora de Laclau. In: LACLAU, Ernesto. A razão populista. São Paulo: Três Estrelas, 2013. 
LUXEMBURGO, Rosa. Huelga de masas, partido y sindicato. Madrid: Fundación Federico Engels, 2003.

MOUFFE, Chantal. Agonistics: Thinking the world politically. London: Verso, 2013.

Democracia, cidadania e a questão do pluralismo. In: Política e Sociedade - Revista de Sociologia Política, vol.1, n.3, Florianópolis: EDUFSC, 2003.

Democratic citizenship and the political community. In: MOUFFE, Chantal (org.). Dimensions of radical democracy: pluralism, Citizenship, Community. London: Verso, 1992.

MOUFFE, Chantal. Hegemony and ideology in Gramsci. In: MOUFFE, Chantal (org.). Gramsci and marxist theory. London: Routledge \&Kegan Paul Ed, 1979.

O regresso do político. Lisboa: Gradiva, 1996.

MOUFFE, Chantal. Politics and Passions: The stakes of democracy. In: Ethical perspectives. disponível em http://www.kuleuven.be/ep/viewpic.php?LAN=E\&TABLE=EP\&ID=139. Acesso em 16 maio 2015.

. Sobre o político. São Paulo: Martins Fontes, 2015.

The democratic paradox. London: Verso, 2000.

The importance of engaging the state. In: $\mathrm{PUGH}$, Jonathan (Ed.). What is radical politics today? Basingstoke: Palgrave MacMillan, 2009.

NOGUEIRA, Marco Aurélio. As três ideias de sociedade civil, o Estado e a politização. In: COUTINHO, Carlos Nelson; TEIXEIRA, Andréa de Paula. (org) Ler Gramsci, entender a realidade. Rio de Janeiro: Civilização Brasileira, 2003.

TAMBURRANO, Giuseppe. Gramsci y la hegemonia del proletariado. In: TOGLIATTI, P. et al. (org.) Gramsci y el marxismo. Buenos Aires: Editorial Proteo, 1965.

ZIZEK, Slavoj. Against the populism temptation. In: Critical Inquiry, Chicago, 2006, n. 32:3, p.551-574. Disponível em http://jdeanicite.typepad.com/i_cite/files/zizek_against_the_populist_temptation.pdf. Acesso em 10 jun. 2017. 